\title{
Analog Amplitude Modulation of a High Voltage, Solid State Inductive Adder, Pulse Generator Using MOSFETS
}

\author{
E. J. Gower, J. S. Sullivan
}

This article was submitted to 2002 International Power Modulator Conference, Hollywood, CA. June 30-July 3, 2002

U.S. Department of Energy

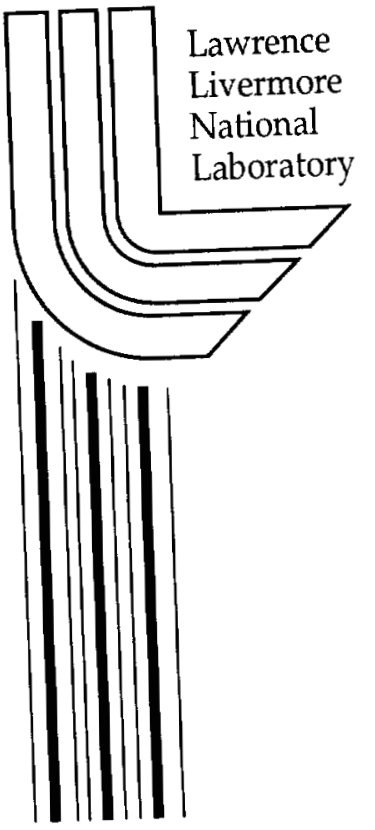

June 24, 2002 


\section{DISCLAIMER}

This document was prepared as an account of work sponsored by an agency of the United States Government. Neither the United States Government nor the University of California nor any of their employees, makes any warranty, express or implied, or assumes any legal liability or responsibility for the accuracy, completeness, or usefulness of any information, apparatus, product, or process disclosed, or represents that its use would not infringe privately owned rights. Reference herein to any specific commercial product, process, or service by trade name, trademark, manufacturer, or otherwise, does not necessarily constitute or imply its endorsement, recommendation, or favoring by the United States Government or the University of California. The views and opinions of authors expressed herein do not necessarily state or reflect those of the United States Government or the University of California, and shall not be used for advertising or product endorsement purposes.

This is a preprint of a paper intended for publication in a journal or proceedings. Since changes may be made before publication, this preprint is made available with the understanding that it will not be cited or reproduced without the permission of the author.

This work was performed under the auspices of the United States Department of Energy by the University of California, Lawrence Livermore National Laboratory under contract No. W-7405-Eng-48.

This report has been reproduced directly from the best available copy.

Available electronically at http://www.doc.gov/bridge

Available for a processing fee to U.S. Department of Energy

And its contractors in paper from

U.S. Department of Energy

Office of Scientific and Technical Information

P.O. Box 62

Oak Ridge, TN 37831-0062

Telephone: (865) 576-8401

Facsimile: (865) 576-5728

E-mail: reports@adonis.osti.gov

Available for the sale to the public from

U.S. Department of Commerce

National Technical Information Service

5285 Port Royal Road

Springfield, VA 22161

Telephone: (800) 553-6847

Facsimile: (703) 605-6900

E-mail: orders@ntis.fedworld.gov

Online ordering: http://www.ntis.gov/ordering.htm

\section{OR}

Lawrence Livermore National Laboratory

Technical Information Department's Digital Library

http://www.llnl.gov/tid/Library.html 


\title{
ANALOG AMPLITUDE MODULATION OF A HIGH VOLTAGE, SOLID STATE INDUCTIVE ADDER, PULSE GENERATOR USING MOSFETS*
}

\author{
E.J. Gower and J.S. Sullivan \\ University of California, Lawrence Livermore National Laboratory \\ P.O. Box 5508, Livermore, CA, 94550 USA
}

\section{Abstract}

High voltage, solid state, inductive adder, pulse generators have found increasing application as fast kicker pulse modulators for charged particle beams. The solid state, inductive adder, pulse generator is similar in operation to the linear induction accelerator. The main difference is that the solid state, adder couples energy by transformer action from multiple primaries to a voltage summing stalk, instead of an electron beam. Ideally, the inductive adder produces a rectangular voltage pulse at the load. In reality, there is usually some voltage variation at the load due to droop on primary circuit storage capacitors, or, temporal variations in the load impedance. Power MOSFET circuits have been developed to provide analog modulation of the output voltage amplitude of a solid state, inductive adder, pulse generator. The modulation is achieved by including MOSFET based, variable subtraction circuits in the multiple primary stack. The subtraction circuits can be used to compensate for voltage droop, or, to tailor the output pulse amplitude to provide a desired effect in the load. Power MOSFET subtraction circuits have been developed to modulate short, temporal $(60-400 \mathrm{~ns})$, voltage and current pulses. MOSFET devices have been tested up to 20 amps and 800 Volts with a band pass of $50 \mathrm{MHz}$. An analog modulation cell has been tested in a five cell high, voltage adder stack.

\section{INTRODUCTION}

MOSFET based, inductive adder pulse generators have been developed for the fast kicker pulse modulator application [1] for charged particle beams. In some instances, amplitude modulation of the fast kicker output voltage pulse is required. The fast kicker voltage amplitude modulation can be accomplished by including additional cells in the inductive adder stack that add, or, subtract voltage from the kicker output pulse in the desired fashion. Two modulation methods have been developed. The "digital" modulation method relies on a number of adder cells that each adds a fixed voltage level to the kicker output pulse amplitude on command. This method is described in detail elsewhere [2]. The "analog" modulation method relies on a number of analog subtraction cells that each subtracts a temporally varying voltage from the kicker output voltage amplitude. The gate drive voltage applied to a power MOSFET array located in the analog subtraction cell determines the temporal variation of the analog cell subtraction voltage. The operation of an analog modulation cell is more easily explained with the aid of Figure 1.

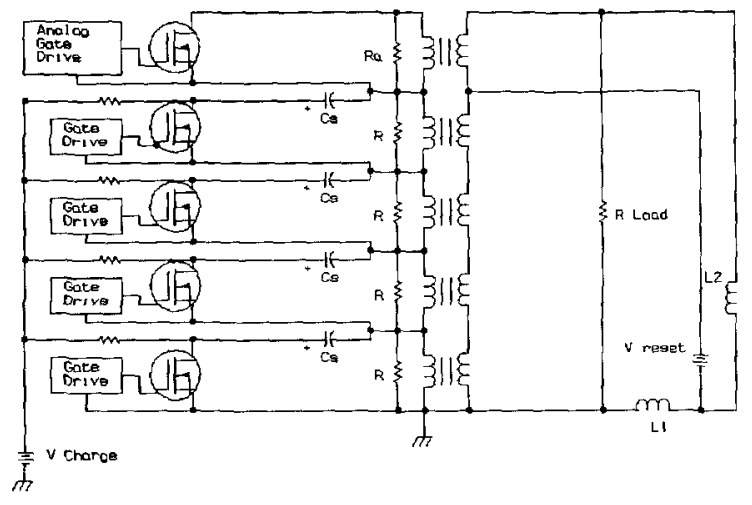

Figure 1. Four Cell Adder with modulation cell

Figure 1 shows an inductive adder stack with four adder cells and one analog modulation cell. If we ignore the analog modulation cell at the top of Figure 1 , the function of the four adder cells can be more easily explained. The adder function of the cells is accomplished through the transformer action of the magnetic cores. Each magnetic core has a single turn primary and secondary. The primaries of each cell (MOSFET side of the magnetic core) are connected electrically in parallel. The secondaries of the cells are connected electrically in series. A voltage of $\mathrm{V}$ Charge appears across each adder cell primary and secondary when the adder cell MOSFETs are gated on. This results in a pulse voltage of $4 \mathrm{~V}$ Charge appearing across the resistor $\mathrm{R}$ Load. The secondary current is $4 \mathrm{~V}$ Charge divided by $\mathrm{R}$ Load. The 
primary current is equal to $4 \mathrm{~V}$ Charge divided by $\mathrm{R}$ Load plus the magnetizing current of the core. If the capacitor, Cs, is sized large enough, there is little voltage droop during the pulse. This results in a rectangular output voltage pulse. If we add the analog modulation circuit as the fifth cell in Figure 1,operation of our adder circuit changes. If the analog MOSFET remains off, the resistor Ra appears as additional impedance in series with $\mathrm{R}$ Load. The voltage that appears across $\mathbf{R}$ Load is reduced to

$$
\mathrm{V}_{\text {load }}=\{\mathrm{R} \mathrm{Load} /(\mathrm{R} \mathrm{Load}+\mathrm{Ra})\} 4 \mathrm{~V}
$$

In effect, a portion of the output load voltage has been subtracted. If we gate the analog modulation MOSFETs completely "on", current is shunted away from the resistor $\mathrm{Ra}$. The voltage that has been developed across $\mathrm{Ra}$ collapses and the output voltage is restored across $\mathrm{R}$ Load. If the analog modulation MOSFETs are only partially gated on, only a portion of voltage developed across $\mathrm{Ra}$ is restored across $\mathrm{R}$ Load. Thus, modulating the current through the analog modulation MOSFETs, via the gate voltage, can modulate the amplitude of the inductive adder output voltage. The analog modulation concept, although simple, requires MOSFETs and gate drive circuitry with sufficient bandwidth and current carrying capability to be successful.

\section{Initial Testing}

Initial tests consisted of identifying candidate MOSFETs and developing a practical, high bandwidth, surface mount, integrated circuit based, MOSFET gate drive circuitry. Our goal was to find power MOSFETs with a bandwidth of $50 \mathrm{MHz}$. The MOSFET under test was connected in parallel to a $25-\mathrm{Ohm}$ resistor. A 200 Volt, $150 \mathrm{~ns}$ wide pulse was applied across the 25 - Ohm resistor and across the drain to source of the MOSFET under test. A voltage pulse was applied to the MOSFET gate during the application of the 200 Volt pulse. The gate pulse consisted of a 4-5 Volt pedestal and a 3 Volt, peak to peak, amplitude square-wave at frequencies of 25,35 and $50 \mathrm{MHz}$. The voltage across the $25-\mathrm{Ohm}$ resistor was recorded to determine how well the MOSFET had modulated this voltage. Eight different candidate MOSFETs from six different manufacturers were tested in this manner. The most promising devices identified for this application were the ARF446 and ARF449A from Advanced Power Technology. The ARF446 and 449A MOSFETs are rated at 900 Volts and 6.5 Amperes and 450 Volts and 9 Amperes, respectively [3]. However, the ARF 449A clearly had the best frequency response of all the devices tested.

The gate drive circuit used for the initial MOSFET tests was the preamplifier for the control grid in a hard tube modulator circuit. This device was a $100 \mathrm{MHz}$ bandwidth, linear amplifier that could provide a positive 15 Volt output and source up to 20 Amperes of drive current. This gate drive circuit was impractical due to cost and size. A practical, integrated circuit based, MOSFET gate drive circuit, that was designed and fabricated for the analog modulation application, is shown in Figure 2.

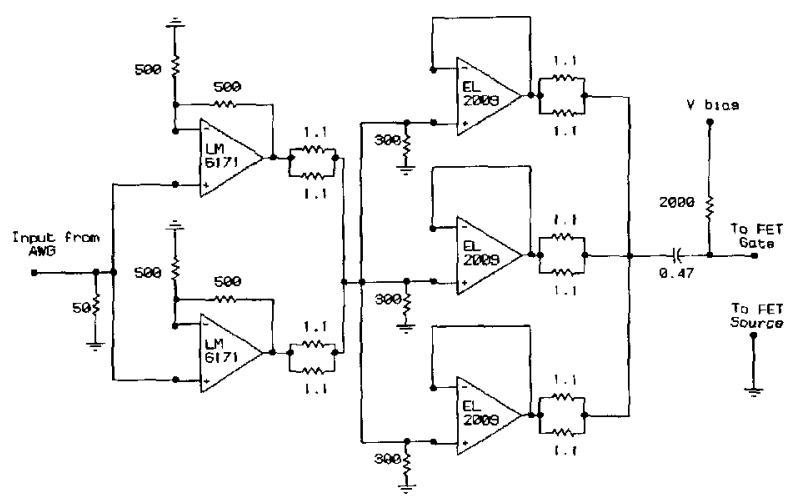

Figure 2. Linear Gate Drive

This circuit drives one analog modulation MOSFET gate. This circuit can source a peak drive current of 5.4 Amperes producing maximum rates of gate voltage rise of $4.5 \mathrm{~V} / \mathrm{ns}$ and $3.0 \mathrm{~V} / \mathrm{ns}$ for the ARF 449A and 446, respectively. An arbitrary waveform generator is used to drive the input of this circuit. MOSFET current modulation tests were performed after identifying the candidate devices and fabricating the gate drive circuit.

\section{MOSFET Current Modulation Tests}

The MOSFET drain current modulation tests were performed on the ARF 449A using the circuit shown in Figure 3.

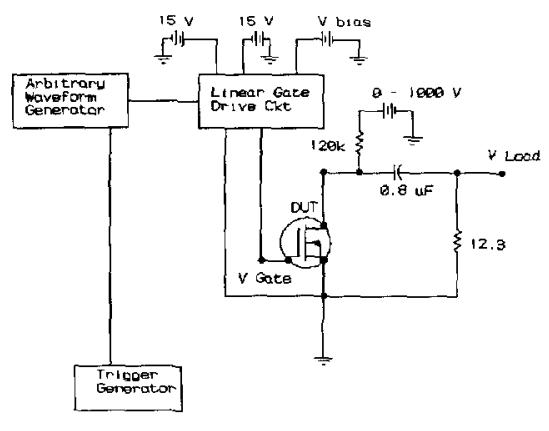

Figure 3. Current Modulation Test Circuit

This figure shows an energy storage capacitor of $0.8 \mathrm{uF}$, charged to 425 Volts, connected in series with 
the ARF 449A and a load resistor of $12.3 \mathrm{Ohms}$. The load resistor limited the maximum current in the circuit to 32 amperes. Our intent with these tests was to determine the current modulation capability of the ARF 449A for currents of a few tens of Amperes. When the drain current rises to the level of one to two amperes, or greater, the ARF 449A is being operated in the velocity saturation regime. This mode of operation results in a drain current for the ARF449A that is linearly dependent on the gate to source voltage minus the device threshold voltage. A variety of gate drive voltage waveforms were applied to modulate the circuit current and, hence, the load voltage. The current through the ARF449A was ramped up, ramped down, ramped up and down and varied sinusoidally for pulse widths that varied from 370 to 100 ns. For brevity, we include two sets of waveforms that show the gate voltage and drain current for the ARF 449A for the case of a $50 \mathrm{MHz}$ sinusoidal gate voltage and a 25 ns ramp-up, ramp-down, ramp-up and ramp-down. These two cases are shown in Figure 4 and 5 . These two cases represent the best current modulation that we were able to accomplish with the ARF 449A.
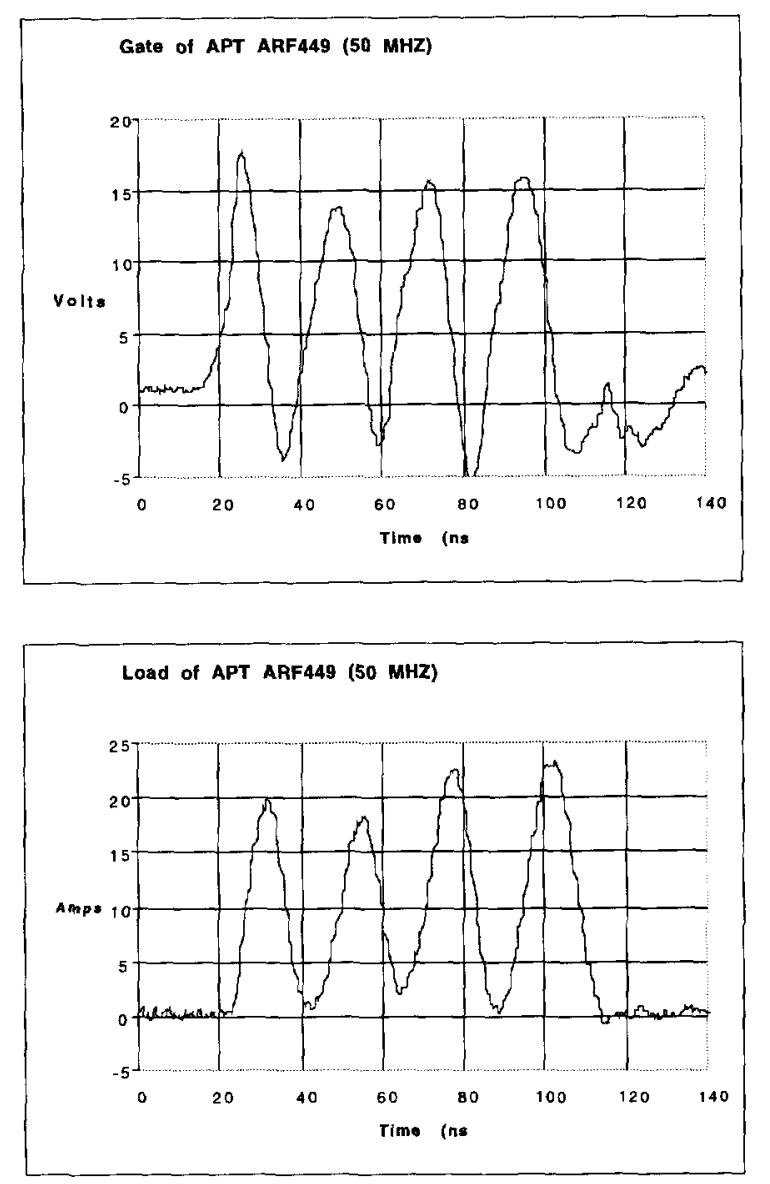

Figure 4. $50 \mathrm{MHz}$ Sinusoidal Modulation

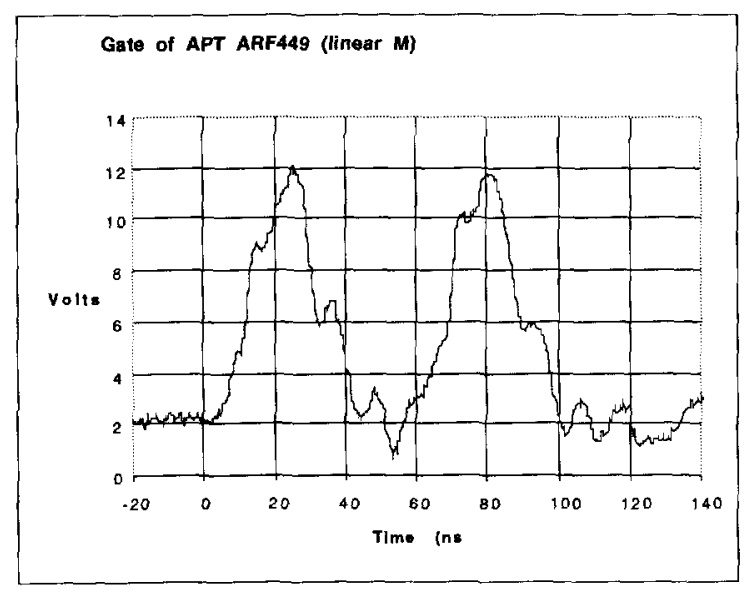

Load of APT ARF449 (Linear M)

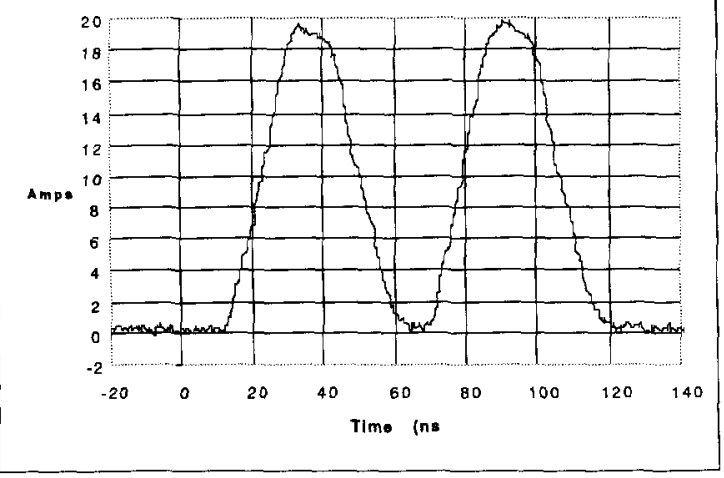

Figure 5. Ramp-Up, Ramp-Down Modulation

\section{PHASE 3 TESTS}

A 5-cell adder circuit, similar to the arrangement in Figure 1, was constructed to test the analog modulation concept. Four analog modulation MOSFETs were installed for the initial tests of the 5cell adder circuit. The analog modulation MOSFETs had a total modulation capability of 80 Amperes. The initial load on the output of the 5-cell adder was 22.5 - Ohms. The four adder cells were operated at charge voltages that would keep the maximum voltage applied to the 22.5 - Ohm load in the range of 1600 to 2000 volts. Figure 6 shows the drain voltage of the analog modulation MOSFETs and the output voltage of the 5-cell adder for a $20 \mathrm{MHz}$ square wave applied to the input of the gate drive circuit. An approximately 250 Volt, $20 \mathrm{MHz}$ pulse train appears across the analog modulation MOSFETs. This pulse train appears as 200 Volt bites out of the flat top of the 5-cell adder output pulse. The voltage bites on the 5 -cell adder output pulse are more rounded and reduced in amplitude from the modulating voltage 
pulses. This rounding of the subtraction voltage has been attributed to the L/R time constant of the 5-cell adder and the load resistor.

The parallel modulation circuits were increased from four to nine, increasing the current modulation capability. The charge voltage on the adder cell was increased to obtain output pulses of 2800 to 3000 Volts and the load resistor was decreased to 17.3 - Ohms. Figure 7 shows the $20 \mathrm{MHz}$ square wave test repeated. Now, we see the full subtraction voltage being taken from the adder output pulse. However, the effect of the $L / R$ time constant is more pronounced due to the decrease in load resistance. The analog modulation circuitry is switching 130 Amperes on and off at $20 \mathrm{MHz}$. The analog modulation circuitry is capable of switching 130 Amperes at 30 $\mathrm{MHz}$, but the low pass filter formed by the inductance of the stack and the load resistor prevent any useful modulation above $20-25 \mathrm{MHz}$.
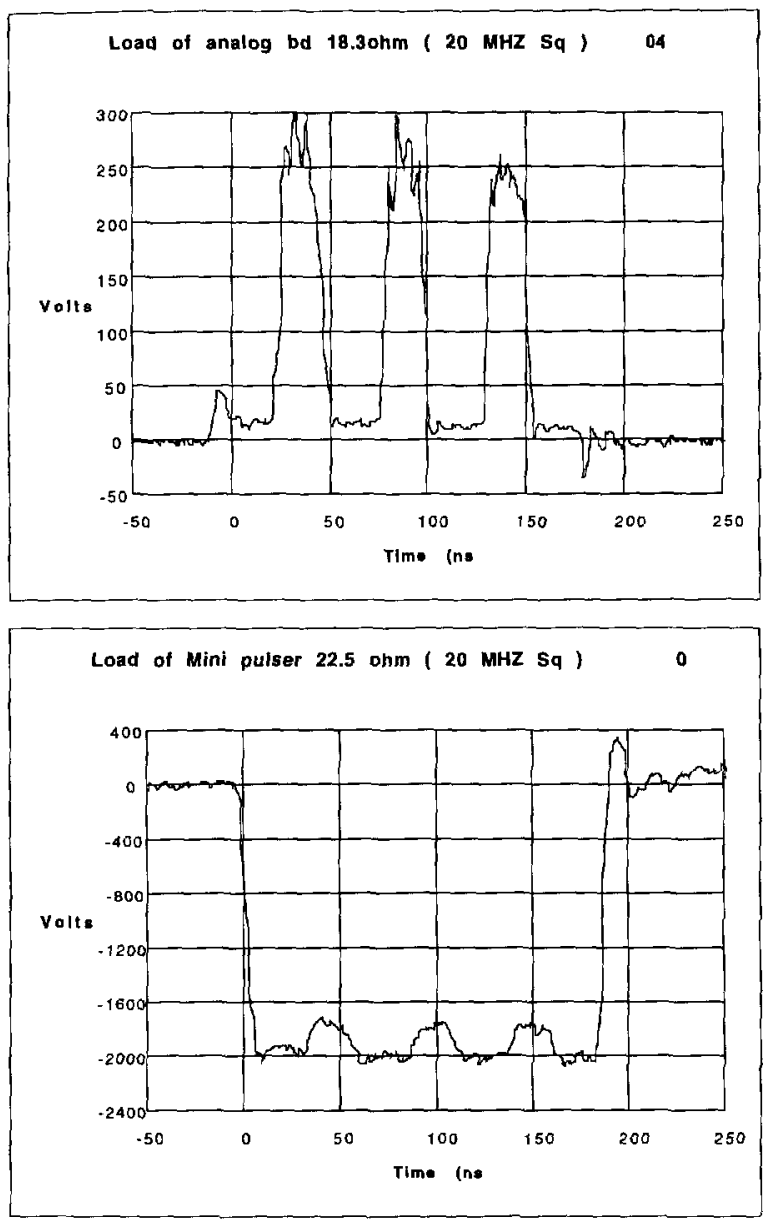

Figure 6. Low Current 20 MHz Square Wave Test

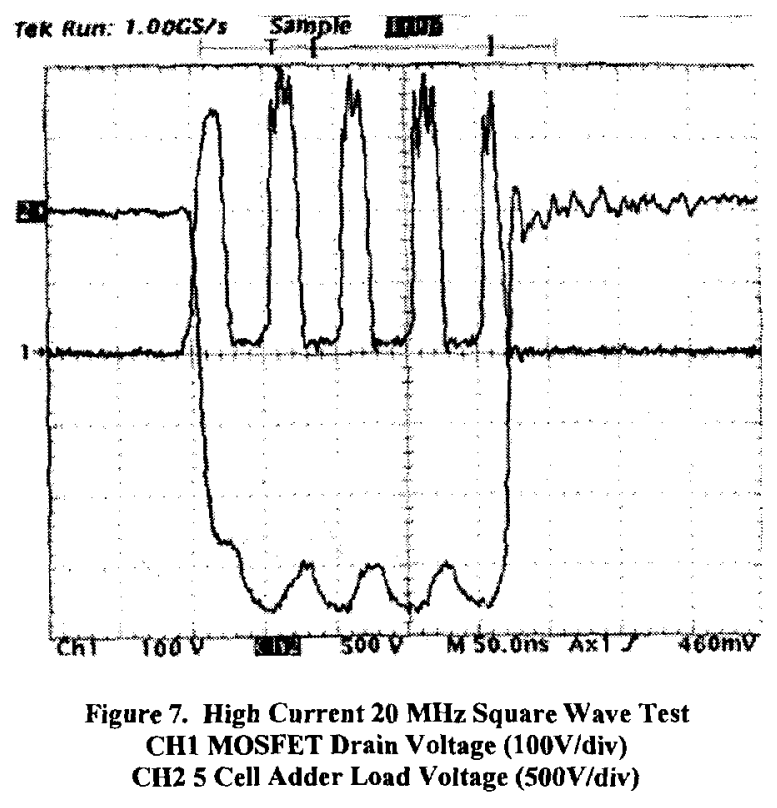

\section{CONCLUSION}

We have identified commercially available MOSFETs that have a power bandwidth of $50 \mathrm{MHz}$. We have developed drive circuitry capable of modulating voltage of power MOSFETs to enable modulation of 20 amperes of current per MOSFET at $50 \mathrm{MHz}$ in bench tests. We have constructed a 5 cell adder stack and successfully modulated 300 Volt amplitudes on 3000 Volt pulses.

\section{REFERENCES}

[1] Ed Cook, et al, "Solid State Kicker Pulser for DAHRT-2*," Lawrence Livermore National Laboratory, Livermore CA

[2] J.A. Watson, et al, "A Solid-State Modulator for High Speed Kickers*," Lawrence Livermore National Laboratory, Livermore CA

[3] Advanced Power Technology Inc. "Data Sheets" 